Received: July 5, 2017

Revision received: June 2, 2018

\title{
Analysis of Effect of Fashion Design Teaching Method Reform from a Modern Aesthetic Perspective
}

\author{
Bojia Lu ${ }^{1}$ \\ Northeast Electric Power University
}

\begin{abstract}
Currently the industry of fashion design is dominated by instrumentalism and utilitarianism though implementation of aesthetic thought is very important for fashion design teaching. Based on the theoretic foundation of Schiller's aesthetic thought, and with a perspective of modern aesthetics, this paper studies the effect of teaching method reform using questionnaires on attendees of design programs from three colleges. Results show that after the teaching method reform, there are issues such as oversight of aesthetic though education, loss of free spirit, and insufficient perception of beauty and innovation. To address these issues, we should utilize heuristic teaching, game-based teaching, and experimental teaching in order to achieve better learning efficiency, enhanced role of aesthetic thought in skill, competence, and moral education, and construction of humanity-oriented teaching concepts and systematic culture. This research serves to provide reference for further fashion design teaching reform in China.
\end{abstract}

\section{Keywords}

Modern Aesthetics $\bullet$ Fashion Design • Teaching Method Reform • Effect Analysis

\footnotetext{
${ }^{1}$ Correspondence to: Bojia Lu (MA), Lecturer, Clothes and Accessories Design Specialty, Art College, Northeast Electric Power University, Jilin 132011, China. Email: lubojia235@163.com
} 
Fashion design education is closely related to people's lifestyles and stage of social development. It is highly comprehensive. As the society is in an age of much enhanced material wealth and productivity, people's needs for garment have changed from seeking warmth and decency to expressing and pursuing fashion and beauty. Along with development of all forms of design tools and techniques, fashion design education is subject to the tool logics of techniques (Volino, \& Magnenat-Thalmann, 2005). The teaching priorities are placed on training of techniques and know-how instead of aesthetic thought, which has resulted in insufficient creativity among students.

China's colleges started the first enrollment of fashion design students in 1980. The department of dyeing and weaving of the Central Academy of Design and Fine Arts had its first enrollment of college-degree students in that year, and enrolled the first bachelor's degree students in 1982. Following that, colleges in China started their own programs in fashion design (Lai, University, \& University, 2014). Due to insufficient teaching experience and faculty resources, China did not have unified standards on teaching goals, system, content and method for the fashion design programs until the mid of 1990s when fashion colleges launched reform on teaching to address society's needs for talents (Boaler, 2002). After three decades, fashion education reform has shown results in the $21^{\text {st }}$ century with a much-improved teaching method and system which is suitable to the needs of industry. But the gaps are still outstanding against developed countries in terms of teaching content and concepts (Minmin, 2013). Overall, we find that the fashion design education is dominated by two trends, "art is supreme" and "technique is supreme" (Salvato, 2008). Those upholding that "art is supreme" mechanically integrate painting with techniques, obscure the line between art and design, and oversee the connection of garment-design with technique and sales (Patel, V. L. et all, 2009), while those upholding "technique is supreme" highlight teaching of techniques. This method is effective in terms of fast teaching result but lacks cultivation of creativity and regenerative thinking, so they are imitators at most, rather than artists with adequate aesthetics (Grossmann, 1968).

From these analyses, based on literature review and a modern perspective on aesthetics, this paper conducts survey on the effect of teaching method reform among fashion design students from three universities in China, including Beijing Institute of Fashion Technology, Xi'an Academy of Fine Arts and Wuhan Textile University.

\section{Analysis on Effect of Teaching Method Reform from a Modern Aesthetic Perspective}

Under the backdrop of educational reform, fashion design programs are undergoing reform on teaching methods. Based on the conventional class-room teaching, varied teaching methods such as case study, heuristic teaching, project-based teaching have been introduced to fashion design programs (Claude, 2001). This paper uses a modern aesthetic perspective and selects students from fashion design programs from three Chinese universities, including Beijing Institute of Fashion Technology, Xi'an Academy of Fine Arts and Wuhan Textile University for surveying. 200 questionnaires were delivered, and 180 of them were effectively recollected. We conducted statistically analysis of the survey results and concluded issues concerning the teaching reform and its effect. 


\section{Survey on Current Situation of Fashion Design Teaching from a Modern Aesthetic Perspective}

Survey on Current Situation of Aesthetic Education. Colleges should offer art and art theory classes to improve students' cultural competency, in addition to the design classes and project-based classes. But some universities do not offer any or offer few theory classes. Even if they do, effect of these classes is less-thansatisfactory. Fig 1 includes results on the art theory classes and the effect. We can see that about $60 \%$ of surveyed students think these classes are a little helpful, while $21 \%$ students think they are very helpful. It shows that even if aesthetic classes are offered by universities, the effect is not satisfactory.

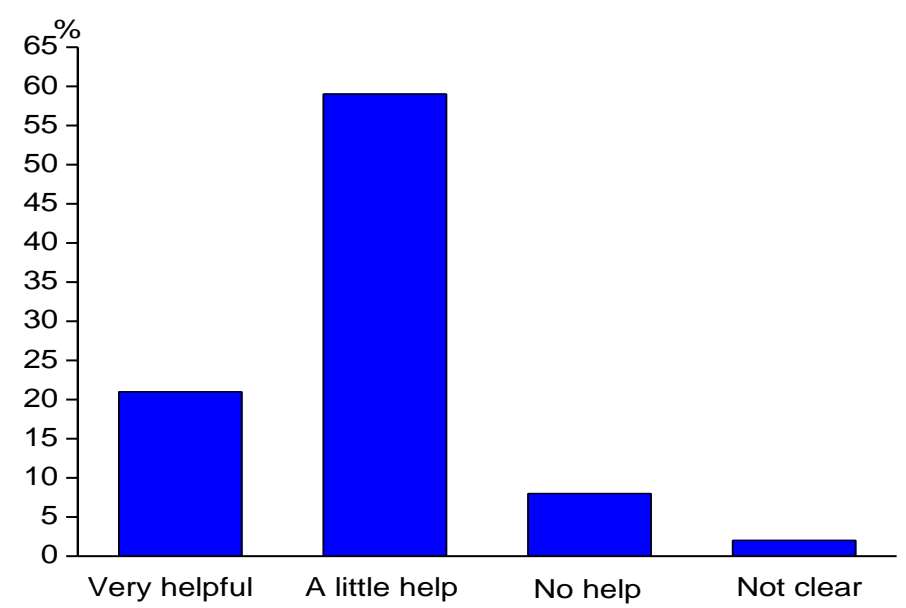

Figure 1. Statistics on the effects of art and art theory classes.

Whether Students Go to Art Lectures? From results on whether students go to art lectures in Fig 2, 34.2\% of them have never attended any art lectures, and about $50 \%$ go to 1 or 2 lectures every semester.

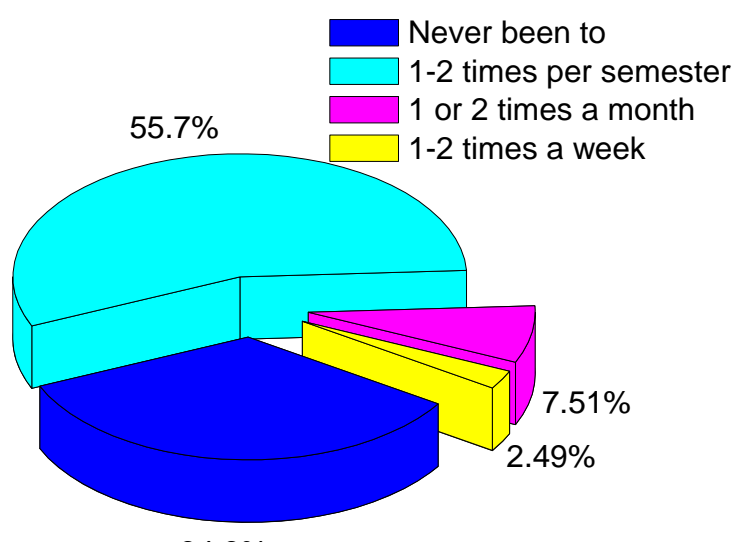

$34.3 \%$

Figure 2. Do you often listen to lectures about art and culture. 
Heuristic Teaching. From results on heuristic teaching in Fig 3, 80\% of students think 1 to 3 teachers apply heuristic teaching to inspire them. It shows that during the teaching and learning process, students tend to receive knowledge passively, and teachers fail to engage them in thinking.

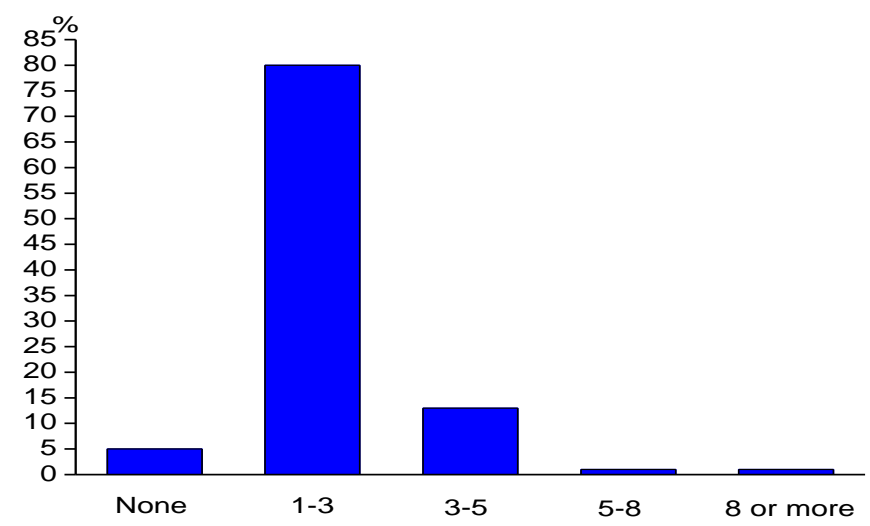

Figure 3. Heuristic teaching teacher statistics.

Classroom Atmosphere. Fig 4 shows results on classroom atmosphere, such as if you have interactions with teachers in class. About $19 \%$ of students think there is no interaction with teachers and classes are not active, while only $13 \%$ rate the class as very active. It means that generally students and teachers have few interactions in class, and class-room activity tends to be unilateral on the teacher's side.

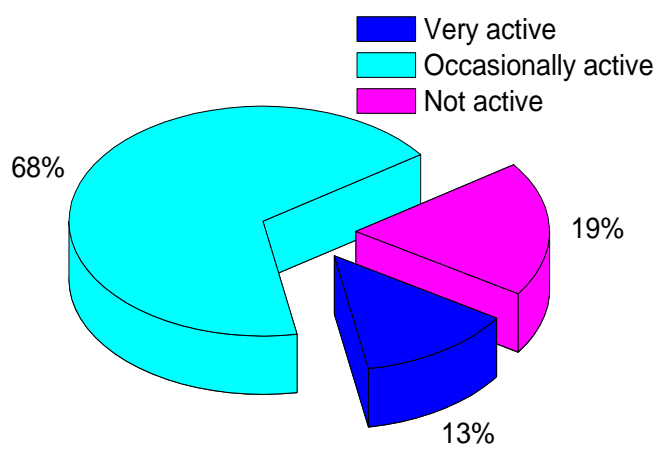

Figure 4. Classroom atmosphere activity statistics.

\section{Issues Observed in Fashion Design Teaching}

Based on the Schiller's aesthetic thought of complete human nature, from a modern aesthetic perspective, and using results from the survey, we have identified the below issues in Fashion Design Teaching.

Oversight of Aesthetic Education. Now the fashion design industry is subject to influence of industrialization and modularization. In teaching, teachers tend to focus on know-hows and skills, and oversee the dominant role of students. Student's initiative and creativity are undermined. 
Loss of Free Spirit. Teaching is supposed to be a two-way activity between teacher and student. Through interactions, students express their views and ideas on fashion design. It is a fundamental right of human being to express freely their ideas, a representation of the significance of education (Holmes, 2013). Current teaching method impedes the teaching and learning experiences.

Insufficient Perception of Beauty and Creativity. As the teaching method reform fails to connect the teaching content with the traditional culture and cutting-edge fashion trends, students cultivated under the concepts of "art is supreme" and "technique is supreme" cannot meet the society's needs for cross-disciplinary talents.

\section{Teaching Method Reform Strategy from a Modern Aesthetic Perspective}

In response to the identified issues in teaching reform, this paper proposes a corresponding strategy for teaching method reform (Kim \& Cho, 2000) as in Fig 5.

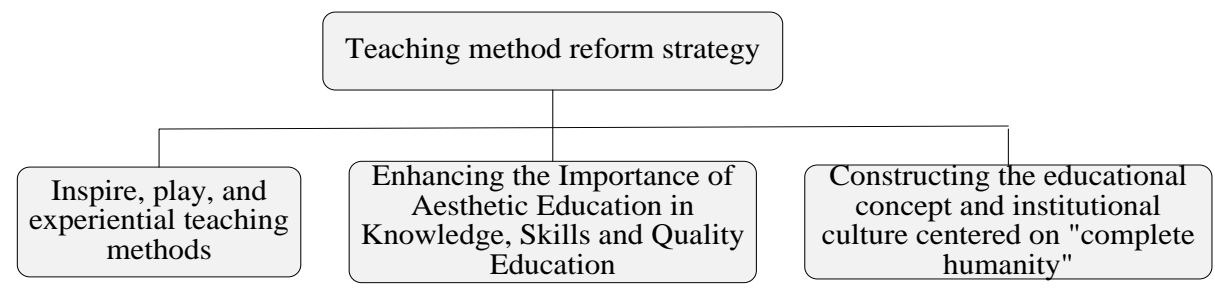

Figure 5. Reform Strategy of Teaching Method of Fashion Design Based on Modern Aesthetic Perspective.

\section{Adopt heuristic, game-based, and experimental teaching method to stimulate student's creativity}

It is a valued approach to stimulate student's emotions during teaching to promote their understanding. Teachers should adopt the heuristic teaching method, stimulate student's emotions, and then break the tradition of one-way teaching. We should focus on providing tailored teaching, respect student's nature, inspire their interests, and teach while playing. Teaching should be a process for students to explore their understanding of art and beauty, not to impose teacher's personal preferences and styles on them.

\section{Enhance importance of aesthetic education in skill competence education}

Fashion design stands for integration of material and ideas. Exceptional designs call for perfect collaboration of practice and creative thinking. Aesthetic education is the way to inspire people's imagination and creativity, and release the power of life and artistic creation through synergizing know-how and skills. It is important that aesthetic education is included and enhanced in fashion design teaching in order to cultivate comprehensive competency in students.

\section{Construct "complete human nature" teaching concept and systematic culture}

We should encourage cultivation of talents with comprehensive competency and improve the teaching concepts and systems around complete human nature. Educational programs should integrate teaching and 
research, professional know-how and comprehensive competency. Students should be encouraged to interact with each other and with teachers. An experimental teaching concept with dual dominant players should be established. Additionally, we should enhance the participation of practice activities, and promote a teaching/practice concept that integrates activities in and outside of classroom, theory and practices. A sound curriculum should be established and the faculty teams should be enhanced.

\section{Conclusion}

Fashion design teaching is a new topic in China. Under the backdrop of higher education reform, this area is also subject to teaching reform. This paper has below conclusions from a modern aesthetic perspective on the effect of teaching method reform.

The survey results show that the aesthetic classes offered by fashion design programs are ineffective, inactive, and conducted using unilateral teaching method.

With reference to Schiller's aesthetic thoughts on "complete human nature", from a modern aesthetic perspective, this paper concludes issues including oversight of aesthetic education, loss of free spirit, and insufficient perception and creativity of beauty in students based on the survey results.

We proposed improvement strategy from teaching method, concept and enhancing role of aesthetic education to address the issues identified in fashion design teaching.

\section{References}

Boaler, J. (2002). Learning from teaching: exploring the relationship between reform curriculum and equity. Journal for Research in Mathematics Education, 33(4), 239-258.

Claude, B. (2001). The creative dilemma: the influence of schiller's aesthetics on the life and work of Otto rank. Journal of Religion \& Health, 40(1), 41-59. http://dx.doi. org/ 10.1023/A:1012530222122

Grossmann, W. (1968). Schiller's aesthetic education. Journal of Aesthetic Education, 2(1), 31-41.

Holmes, T. M. (2013). Property and politics in schiller's theory of aesthetic education. Oxford German Studies, (1), 27-39.

Kim, H. S., \& Cho, S. B. (2000). Application of interactive genetic algorithm to fashion design. Engineering Applications of Artificial Intelligence, 13(6), 635-644. http://dx.doi. org/ 10.1016/S0952-1976(00)00045-2

Minmin. (2013). Rational thinking of computer software teaching reform of art design major. International Journal of Technology Management, 13-15.

Patel, V. L., Yoskowitz, N. A., \& Arocha, J. F. (2009). Towards effective evaluation and reform in medical education: a cognitive and learning sciences perspective. Advances in Health Sciences Education, 14(5), 791-812.

Lai, Q.F., University, C. N., \& University, Z. N. (2014). Chinese translations of schiller's letter on aesthetic education. Journal of Aesthetic Education. 
Salvato, N. (2008). Competition as an effective education reform. Heart, 94(10), 1342-9.

Volino, P., Cordier, F., \& Magnenat-Thalmann, N. (2005). From early virtual garment simulation to interactive fashion design. Computer-Aided Design, 37(6), 593-608. http://dx.doi. org/ 10.1016/j.cad.2004.09.003 